\title{
Suboptimal validity of amyloid imaging-based diagnosis and management of Alzheimer's disease: why it is time to abandon the approach
}

\author{
Abass Alavi ${ }^{1}$ • Jorge R. Barrio ${ }^{2}$ - Thomas J. Werner ${ }^{1}$ - Mohsen Khosravi ${ }^{3}$ - Andrew Newberg ${ }^{3,4}$. \\ Poul Flemming Høilund-Carlsen ${ }^{5,6}$
}

Published online: 31 October 2019

(C) Springer-Verlag GmbH Germany, part of Springer Nature 2019

The broken limits to life expectancy observed in the last few decades have imposed an increasing medical, social and financial burden on society [1], as a result of the growing incidence of Alzheimer's disease (AD) and other neurological diseases. The introduction of modern imaging techniques in the $1970 \mathrm{~s}$ and 1980s has provided powerful approaches to detect and characterize these disorders by visualizing changes at the structural and molecular levels in the brain $[2,3]$. By now it is well understood that biochemical changes precede anatomical abnormalities in neurological diseases [4]. Thus, diseases like AD cannot be visualized in their earlier stages by structural imaging techniques such as computed tomography (CT) or magnetic resonance imaging (MRI). In patients with proven $\mathrm{AD}$, by the time structural abnormalities such as ventricular enlargement and cortical atrophy are detected by CT or MRI, the disease process has reached advanced stages and therefore will be already associated with significant cognitive impairment [5].

This article is part of the Topical Collection on Neurology

Abass Alavi

abass.alavi@uphs.upenn.edu

1 Department of Radiology, Hospital of the University of Pennsylvania, 3400 Spruce Street, Philadelphia, PA 19104, USA

2 David Geffen UCLA School of Medicine, Los Angeles, CA 90095, USA

3 Department of Radiology, Thomas Jefferson University, Philadelphia, PA, USA

4 Department of Integrative Medicine and Nutritional Sciences, Marcus Institute of Integrative Health, Thomas Jefferson University, Philadelphia, PA 19107, USA

5 Department of Nuclear Medicine, Odense University Hospital, Odense, Denmark

6 Department of Clinical Research, University of Southern Denmark, Odense, Denmark
The introduction of 2-deoxy-2-[F-18]fluoro-D-glucose (FDG) (first developed at the University of Pennsylvania in the 1970's in conjunction with Brookhaven National Laboratories - BNL) as a biomarker for the quantitative assessment of regional glucose metabolism in the human brain and other organs opened a new era in medical imaging that has resulted in a paradigm shift in medicine [6]. Coincidently, the introduction of powerful Positron Emission Tomography (PET) instruments has enabled visualizing disease activity at the molecular level in many organs and in various pathological states [7]. Over the past four decades, numerous PETbased molecular imaging probes have been developed and employed for the detection and characterization of various neuropsychiatric disorders. Since its initial development, a central focus of research with FDG-PET has been in the assessment of cognitive decline, with emphasis on mild cognitive impairment (MCI) and $\mathrm{AD}$, as an indicator of regional neuronal activity. By the late 1970s and early 1980s, investigators at BNL, University of Pennsylvania and UCLA were among the first to assess the role of this powerful technique in detecting early evidence for $\mathrm{AD}$ and compare the results with those from structural imaging techniques such as CT or MRI [8-10]. The imaging patterns seen on FDG-PET follow the default mode network (DMN), an anatomically defined brain network involving the medial temporal lobe and the medial prefrontal subsystems that converge for integration in the posterior cingulate gyrus [11]. These patterns are quite characteristic of this neurodegenerative disease and the use of FDGPET reflecting regional functional activity in the human brain has been validated for detecting early evidence of AD and differentiating it from other dementias [12]. The diagnostic reliability (94\% sensitivity and $76 \%$ specificity to detect progressive dementia; and $93 \%$ sensitivity and $73 \%$ specificity to identify AD, based on direct comparison of FDG-PET results with those of neuropathological evaluation in the same subjects), and the solid scientific foundation of the FDG-PET 
technology over the years [12] eventually led to its FDA approval and reimbursement by the Centers for Medicare \& Medicaid Services (CMS), as well as private insurers in the US and many other countries.

In addition to failing neuronal function, the brain of $\mathrm{AD}$ patients at autopsy reveals characteristic pathognomonic hallmarks involving brain accumulation of extracellular deposits of amyloid beta $(\mathrm{A} \beta)$ peptides and intracellular filamentous aggregates of hyperphosphorylated tau protein, known as neuritic plaques, neurofibrillary tangles, and neuropil threads (Fig. 1) [13-15]. Following the first description of the presence of amyloid $(A \beta)$ plaques in the brain of a patient with $\mathrm{AD}[16,17]$, it is now well established that amyloid $(\mathrm{A} \beta)$ plaques may be seen early in the course of the disease [14]. However, the experience gained over the years has revealed that amyloid plaques are also frequently noted in normal aging without clinical or imaging evidence for $\mathrm{AD}$ [18].

In the early 1990s, the "amyloid hypothesis" was introduced with the essential claim that brain amyloid plaque deposition is causative of $\mathrm{AD}$ and their presence lead to neuronal degeneration and $\mathrm{AD}$ progression $[19,20]$. This speculative hypothesis gained enormous publicity over the past three decades driven by the social and medical implications of the increasing $\mathrm{AD}$ incidence. With increasing interest and drive from the pharmaceutical industry, substantial investments and research were initiated to develop specific amyloid diagnostic tests [21] and anti-amyloid therapeutic interventions to treat the disease. However, the existing Consortium to Establish a Registry for Alzheimer's Disease (CERAD) criteria for a neuropathological diagnosis of $\mathrm{AD}$ (National Institutes of AgingAlzheimer's Association (NIA-AA)) is not confined to the exclusive presence of amyloid $A \beta$ pathology in the brain, but stresses the importance of both brain tau and $A \beta$ aggregate deposition. These criteria include (A) $\beta$-amyloidosis in the medial temporal lobe; (B) Braak tau pathology stages (I-VI stages); (C) scoring of neuritic plaques in at least five neocortical regions $[22,23]$. Therefore, the $\mathrm{ABC}$ diagnostic criteria established for brain pathology specimens represent a significant challenge to the logic behind the utilization of PET "A $\beta$-specific" imaging probes as AD diagnostic tools, which the literature points to as their intended use [24]. The current PET "A $\beta$-specific" imaging probes cannot meet by definition CERAD criteria B (tau pathology) and, as designed, they do not meet criteria A (detection of $\beta$-amyloidosis in the medial temporal lobe) [25], two fundamental yardsticks for AD diagnosis as established by CERAD.

Unfortunately, in spite of these established considerations, many investigators around the world adopted the use of PET "A $\beta$-specific" imaging probes, and a large number of publications began to appear in the literature in the 2000s and have continued into recent years. Carbon $11\left(\mathrm{t}_{1 / 2}=20 \mathrm{~min}\right)$ was the initial positron emitting radioisotope used to label amyloid agents, but its short half-life posed a problem for commercialization. Therefore, by the mid-2000s, efforts were made to develop other "amyloid specific" PET probes using Fluorine-18 $\left(\mathrm{t}_{1 / 2}=109 \mathrm{~min}\right)$ to facilitate transport to relatively distant locations for imaging [26]. These developments with PET "A $\beta$-specific" imaging probes (either from the 6hydroxybenzothiazole (e.g., ${ }^{11} \mathrm{C}$ PIB, fluoroPIB or flutemetamol) or trans stilbene (e.g., florbetapir and florbetaben) structural families) bypassed the significance of brain tau-pathology in the disease and projected the beginning of a new era in PET imaging for AD [27-29]. Confirmatory multi-center trials were initiated by performing PET "A $\beta$-specific" imaging in terminally ill patients followed by post-mortem examination of their brains to allow comparison of histological results with those of in vivo imaging data [27]. However, these studies were not designed to compare quantitatively regional cortical amyloid imaging data with those of the underlying $A \beta$ pathology throughout the whole brain (with very limited exceptions) [30].

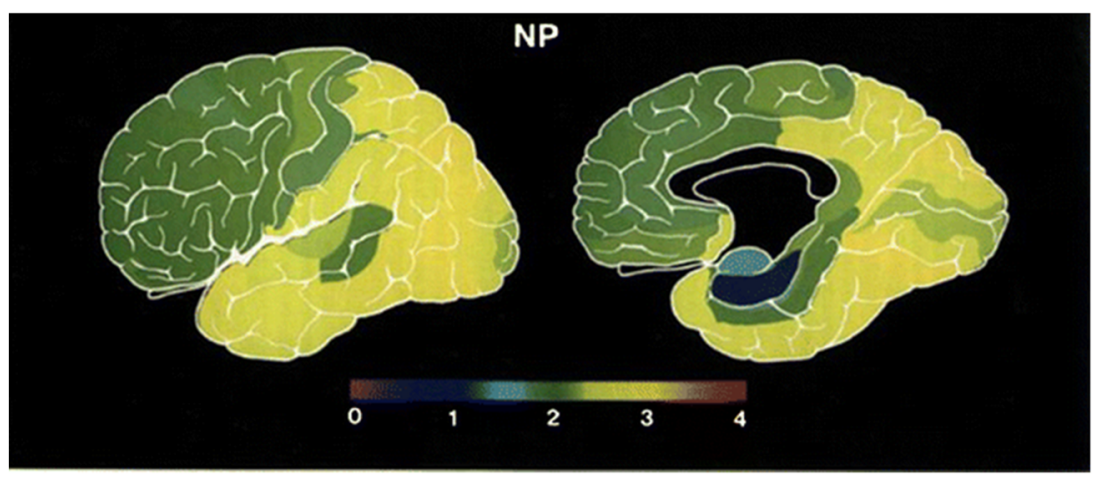

Fig. 1 Neuroanatomical distribution of neuritic plaques in the brain of $\mathrm{AD}$ patients, as revealed by histopathological and immunohistochemical staining. The amyloid burdens are rated on an arbitrary scale of 0 (lowest) to 4 (highest). The typical histopathologically observed pattern of comparatively high concentrations of amyloid in the temporoparietal lobes and the low concentrations in the frontal lobe should be noted and contrasted against the contradictory distribution pattern captured by amyloid imaging (reproduced with permission from Cerebral Cortex, [13]) 
Because of its biased design, which may have also allowed global imaging correlation results with multiple brain targets in terminal stages of the disease, including inflammatory markers, these highly publicized studies were challenged in their validity by investigators and the US Public Citizens, an organization established to protect the public from misleading for-profit organizations.

Subsequently, multicenter trials were conducted to validate the efficacy of ${ }^{18} \mathrm{~F}$-labeled amyloid agents in both controls and AD patients with claims that such imaging methods were highly sensitive and specific for AD. Soon thereafter, applications were made to the FDA for their approval for routine diagnosis and management of patients with $\mathrm{AD}$, but these applications only resulted in the FDA approval for the use of a PET "A $\beta$-specific" probe for ruling out $\mathrm{AD}$ and not for diagnosing $\mathrm{AD}$. CMS subsequently declined reimbursement based on "insufficient evidence to conclude that the use of positron emission tomography (PET) amyloid-beta $(\mathrm{A} \beta)$ imaging is reasonable and necessary for the diagnosis or treatment........and thus PET A $\beta$ imaging is not covered under $\S 1862(a)(1)(A)$ of the Social Security Act ("the Act")."

Over the past several years, we have emphasized the difficulties that are faced in characterizing the underlying causes of $\mathrm{AD}$ with PET $[25,31,32]$. This partly relates to the structural location of uptake of the agents that target these plaques and partly to their non-specific concentration in the adjacent tissues including the white matter. As such, a recent publication comparing results of FDG-PET imaging to those of amyloid scan data, further confirmed the superior performance of FDG-PET and the limitations of "amyloid imaging" in the evaluation of patients with mild cognitive impairment (MCI) and $\mathrm{AD}[33]$.

As a result of this failed attempt for regulatory approval, proponents of the PET amyloid-beta (A $\beta)$ imaging approach urged the CMS to initiate an open-label, longitudinal cohort study called the Imaging Dementia-Evidence for Amyloid Scanning (IDEAS) Study on a large sample $(16,000+)$ of subjects with the intent "to assess patient outcomes." This study is currently in the final stages of completion, but no directives have been established on how PET amyloid-beta $(\mathrm{A} \beta)$ imaging - e.g., as a means to predict the possible development of $\mathrm{AD}$ - would be used in light of the existing scientific and CERAD data indicating the $\mathrm{ABC}$ diagnostic requirements for $\mathrm{AD}[22,23,34]$. Also, no consideration has been given to the emerging evidence that these amyloid-beta $(A \beta)$ imaging probes may target other brain tissues that are not necessarily associated with $\mathrm{AD}$ or other dementias (Fig. 2) [25, 35, 36].

In spite of limitations of $\mathrm{A} \beta$ PET imaging to diagnose $\mathrm{AD}$, it still seemed reasonable to pursue the "amyloid hypothesis" by initiating anti-amyloid-based therapeutic interventions [25]. The logic of the amyloid hypothesis was based on the assumed role of amyloid- $\beta$ plaques in triggering neurodegenerative processes that eventually lead to the cognitive symptoms in patients with $\mathrm{AD}$. In this context, amyloid- $\beta$ plaques are the therapeutic target and therefore it is hypothesized that eliminating these structures would result in cessation of disease progression and possibly cognitive improvement.

The "amyloid hypothesis" has been a central basis of research in this field for more than 25 years and has underpinned much of the research on the diagnosis and treatment of $\mathrm{AD}[19,20]$. Its proponents promised in as early as 2005 that "an effective anti-amyloid strategy will become available for the treatment of Alzheimer's disease within the next few years" [37]. However, the amyloid hypothesis was never uniformly embraced and has been criticized seriously for many years [38]. Critics have argued that amyloid (and neurofibrillary) pathologies are compensatory phenomena, and thus are manifestations of cellular adaptation to inflammation and oxidative stress initiating factor of the disease process [39].

The consistent and systematic failures of a large number of anti-amyloid therapies in the last two decades have raised even more questions about the validity of the amyloid hypothesis. However, the pioneers who introduced this hypothesis and the others who have strongly defended its validity are not yet convinced that the hypothesis may be poorly conceived [40]. They argue that the treatments were started too late to reverse or stop the disease process in recent trials [41]. As a result, much hope was placed on trials that enrolled subjects at risk of AD who have not yet experienced clear-cut symptoms of the disease, including those with an inherited form of the condition [41]. But a recent failure in one of the $\mathrm{AD}$ prevention therapy studies which involved administering a beta-secretase 1 (BACE1), also known as beta-site amyloid precursor protein cleaving enzyme 1 inhibitor, led to discontinuation of the trial. Patients enrolled in the study showed severe side effects and worsening clinical conditions, which raised serious ethical concerns about the safety of anti-amyloid therapeutic approach [42]. Therefore, not only these treatments have shown to be ineffective in improving cognitive function, they have caused some deterioration of the baseline mental abilities. Some of these trials have also shown to be associated with significant MRI-based brain abnormalities (i.e., amyloid-related imaging abnormalities or ARIA), which may explain the findings on neuropsychiatric evaluations of the patients enrolled in these projects.

Diagnostic and therapeutic approaches rooted in the "amyloid hypothesis" have permeated every fiber of $\mathrm{AD}$ research for decades by creating a domain of deceiving intellectual monopoly. These unjustified efforts have affected the decisions of funding agencies and editorial offices, and as such, have prevented the exploration of new ideas and avenues of research [43]. In such circumstances, 


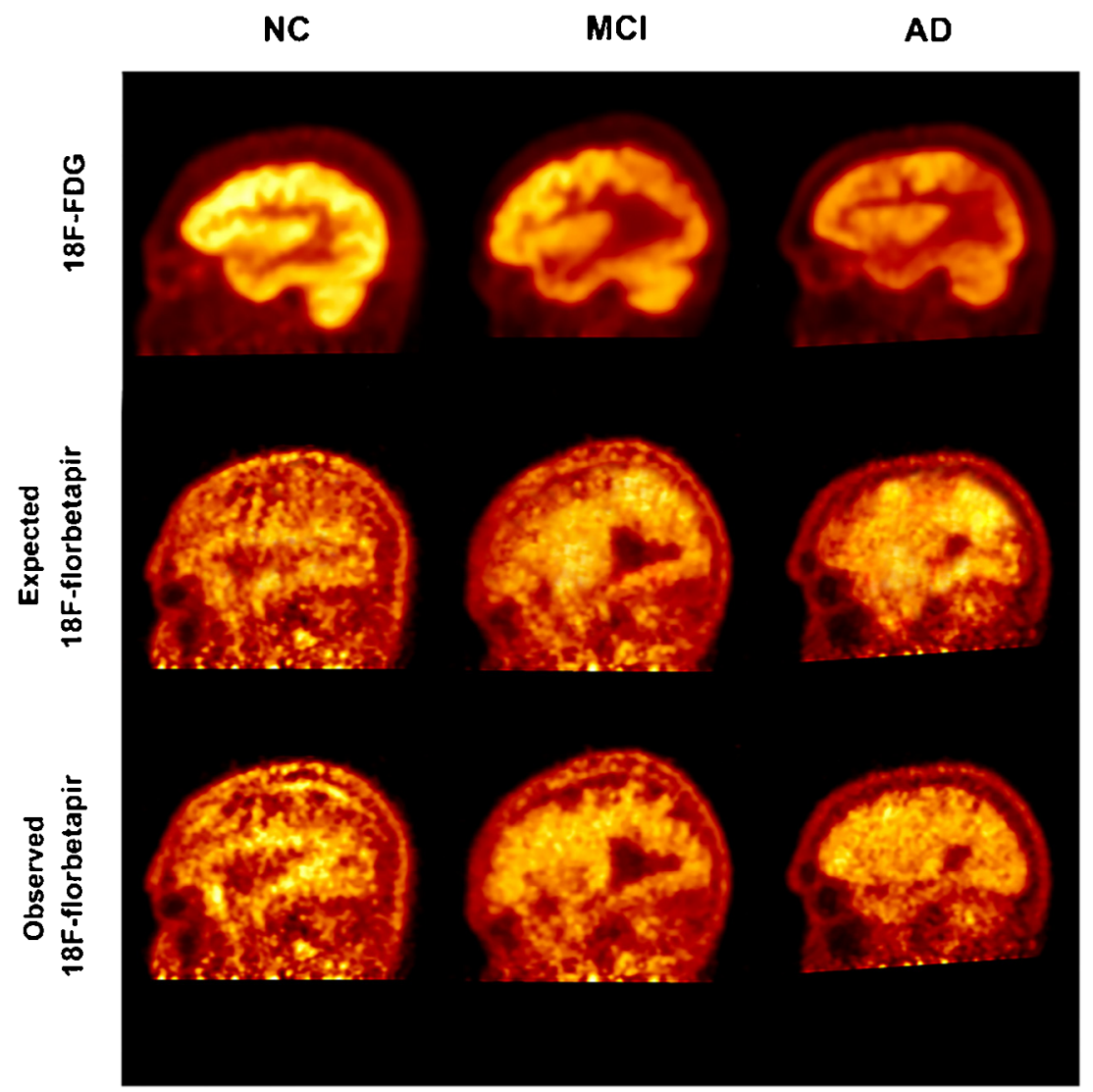

Fig. 2 The top row of FDG-PET sagittal images demonstrates typical metabolic appearance of the frontal, parietal, and temporal lobes in normal controls (NC), mild cognitive impairment (MCI), and Alzheimer's disease (AD) subjects. The middle row images were generated by reversing the patterns in the top row images to demonstrate expected results from PET-based amyloid tracers. In other words, these images are intended to show intense uptake at the lobes where there is significantly reduced glucose metabolism as seen on FDG-PET images. However, the

there is nothing more convincing than the evidence that have been collected after more than 30 years and billions of dollars spent by the funding agencies and pharmaceutical industry about the futility of these unjustified efforts. At this juncture, there is no clear-cut data to support the use of these approaches for either diagnosis or management of AD. Moreover, the severe adverse effects, including detectable brain damage by MRI, as well as acceleration in cognitive decline observed in subjects participating in anti-amyloid therapeutic trials have raised not only medical but also ethical concerns. The proposed use of "amyloid imaging" as a predictor of patient outcomes, when the importance of the amyloid pathology assessment alone is rejected by CERAD criteria for diagnosis of $\mathrm{AD}$, is a source of substantial concern. The psychological impact on volunteers and patients of a medical report with questionable predictive value has also been recently registered in the press [44, 45]. Reports of patients pondering assisted suicides based on these PET "amyloid imaging" bottom row contains observed PET-based amyloid images where the pattern of uptake is significantly different from the expected results with substantial frontal lobe uptake which appears normal on FDG-PET scan. Therefore, it is quite clear that the PET tracers proposed to visualize amyloid plaques are non-specific in nature and cannot be relied upon to determine the underlying causes of cognitive impairment either in patients with $\mathrm{MCI}$ or dementia

results question the justification to continue the ongoing trials [46].

Clearly, it is time to re-evaluate the validity of the amyloid hypothesis, anti-amyloid therapeutic interventions, and "amyloid imaging." Support for new and fresh ideas is needed to prevent additional erosion of trust from the scientific and medical community, as well as that of the public at large in the fight for prevention, control and cure of $\mathrm{AD}$.

Acknowledgments JRB also gratefully acknowledges the support of the Elizabeth and Thomas Plott Chair Endowment in Gerontology.

\section{Compliance with ethical standards}

Conflict of interest The authors declare that they have no conflict of interest.

Ethical approval This article does not contain any studies with human participants or animals performed by any of the authors. 


\section{References}

1. Oeppen J, Vaupel JW. Demography. Broken limits to life expectancy. Science. 2002;296:1029-31. https://doi.org/10.1126/science. 1069675.

2. Lauterbur PC. Image formation by induced local interactions: examples employing nuclear magnetic resonance. Nature. 1973;242: 190-1. https://doi.org/10.1038/242190a0.

3. Richmond C. Sir Godfrey Hounsfield. BMJ. 2004;329:687-.

4. Barrio JR. The molecular basis of disease. In: Phelps ME, editor. PET: molecular imaging and its biological applications: Springer Science \& Business Media; 2004. p. 270-320.

5. Fazekas F, Alavi A, Chawluk JB, Zimmerman RA, Hackney D, Bilaniuk L, et al. Comparison of CT, MR, and PET in Alzheimer's dementia and normal aging. J Nucl Med. 1989;30: 1607-15.

6. Alavi A, Reivich M. Guest editorial: the conception of FDG-PET imaging. Semin Nucl Med. 2002;32:2-5. https://doi.org/10.1053/ snuc.2002.29269.

7. Ter-Pogossian MM, Phelps ME, Hoffman EJ, Mullani NA. A positron-emission transaxial tomograph for nuclear imaging (PETT). Radiology. 1975;114:89-98. https://doi.org/10.1148/114. 1.89 .

8. Alavi A, Reivich M, Ferris S, Christman D, Fowler J, MacGregor $\mathrm{R}$, et al. Regional cerebral glucose metabolism in aging and senile dementia as determined by $18 \mathrm{~F}$-deoxyglucose and positron emission tomography. Exp Brain Res. 1982;(Suppl 5):187-95. https:// doi.org/10.1007/978-3-642-68507-1 26.

9. Kuhl DE, Metter EJ, Riege WH, Phelps ME. Effects of human aging on patterns of local cerebral glucose utilization determined by the $[18 \mathrm{~F}]$ fluorodeoxyglucose method. J Cereb Blood Flow Metab. 1982;2:163-71. https://doi.org/10.1038/jcbfm.1982.15.

10. Jolles PR, Chapman PR, Alavi A. PET, CT, and MRI in the evaluation of neuropsychiatric disorders: current applications. J Nucl Med. 1989;30:1589-606.

11. Vlassenko AG, Vaishnavi SN, Couture L, Sacco D, Shannon BJ, Mach RH, et al. Spatial correlation between brain aerobic glycolysis and amyloid-beta (Abeta) deposition. Proc Natl Acad Sci U S A. 2010;107:17763-7. https://doi.org/10.1073/pnas.1010461107.

12. Silverman DH, Small GW, Chang CY, Lu CS, Kung De Aburto MA, Chen W, et al. Positron emission tomography in evaluation of dementia: regional brain metabolism and long-term outcome. Jama. 2001;286:2120-7. https://doi.org/10.1001/jama.286.17.2120.

13. Arnold SE, Hyman BT, Flory J, Damasio AR, Van Hoesen GW. The topographical and neuroanatomical distribution of neurofibrillary tangles and neuritic plaques in the cerebral cortex of patients with Alzheimer's disease. Cereb Cortex. 1991;1:103-16. https:// doi.org/10.1093/cercor/1.1.103.

14. Braak H, Braak E. Neuropathological stageing of Alzheimerrelated changes. Acta Neuropathol. 1991;82:239-59. https://doi. org/10.1007/bf00308809.

15. Nagy Z, Esiri MM, Jobst KA, Morris JH, King EM, McDonald B, et al. Relative roles of plaques and tangles in the dementia of Alzheimer's disease: correlations using three sets of neuropathological criteria. Dementia. 1995;6:21-31.

16. About a peculiar disease of the cerebral cortex. By Alois Alzheimer, 1907 (Translated by L. Jarvik and H. Greenson). Alzheimer Dis Assoc Disord. 1987;1:3-8.

17. Alzheimer A. Uber eine eigenartige Erkrankung der Hirnrinde. Zentralbl Nervenh Psych. 1907;18:177-9.

18. Davis DG, Schmitt FA, Wekstein DR, Markesbery WR. Alzheimer neuropathologic alterations in aged cognitively normal subjects. $\mathrm{J}$ Neuropathol Exp Neurol. 1999;58:376-88. https://doi.org/10.1097/ 00005072-199904000-00008.
19. Hardy J. The amyloid hypothesis for Alzheimer's disease: a critical reappraisal. J Neurochem. 2009;110:1129-34. https://doi.org/10. 1111/j.1471-4159.2009.06181.x.

20. Selkoe DJ. Normal and abnormal biology of the beta-amyloid precursor protein. Annu Rev Neurosci. 1994;17:489-517. https://doi. org/10.1146/annurev.ne.17.030194.002421.

21. Klunk WE, Debnath ML, Pettegrew JW. Development of small molecule probes for the beta-amyloid protein of Alzheimer's disease. Neurobiol Aging. 1994;15:691-8.

22. Hyman BT, Phelps CH, Beach TG, Bigio EH, Cairns NJ, Carrillo $\mathrm{MC}$, et al. National Institute on Aging-Alzheimer's Association guidelines for the neuropathologic assessment of Alzheimer's disease. Alzheimers Dement. 2012;8:1-13. https://doi.org/10.1016/j. jalz.2011.10.007.

23. Montine TJ, Phelps CH, Beach TG, Bigio EH, Cairns NJ, Dickson DW, et al. National Institute on Aging-Alzheimer's Association guidelines for the neuropathologic assessment of Alzheimer's disease: a practical approach. Acta Neuropathol. 2012;123:1-11. https://doi.org/10.1007/s00401-011-0910-3.

24. Grundman M, Pontecorvo MJ, Salloway SP, Doraiswamy PM, Fleisher AS, Sadowsky CH, et al. Group ftA-AS. Potential impact of amyloid imaging on diagnosis and intended management in patients with progressive cognitive decline. Alzheimer Dis Assoc Disord. 2013;27:4-15. https://doi.org/10.1097/WAD. 0b013e318279d02a.

25. Kepe V, Moghbel MC, Langstrom B, Zaidi H, Vinters HV, Huang $\mathrm{SC}$, et al. Amyloid-beta positron emission tomography imaging probes: a critical review. J Alzheimers Dis. 2013;36:613-31. https://doi.org/10.3233/jad-130485.

26. Wong DF, Rosenberg PB, Zhou Y, Kumar A, Raymont V, Ravert HT, et al. In vivo imaging of amyloid deposition in Alzheimer disease using the radioligand 18F-AV-45 (florbetapir [corrected] $\mathrm{F}$ 18). J Nucl Med. 2010;51:913-20. https://doi.org/10.2967/jnumed. 109.069088.

27. Clark CM, Schneider JA, Bedell BJ, Beach TG, Bilker WB, Mintun MA, et al. Use of florbetapir-PET for imaging beta-amyloid pathology. Jama. 2011;305:275-83. https://doi.org/10.1001/jama.2010. 2008.

28. Mathis CA, Mason NS, Lopresti BJ, Klunk WE. Development of positron emission tomography beta-amyloid plaque imaging agents. Semin Nucl Med. 2012;42:423-32. https://doi.org/10. 1053/j.semnuclmed.2012.07.001.

29. Mathis CA, Wang Y, Klunk WE. Imaging beta-amyloid plaques and neurofibrillary tangles in the aging human brain. Curr Pharm Des. 2004;10:1469-92. https://doi.org/10.2174/ 1381612043384772 .

30. Ikonomovic MD, Klunk WE, Abrahamson EE, Mathis CA, Price JC, Tsopelas ND, et al. Post-mortem correlates of in vivo PiB-PET amyloid imaging in a typical case of Alzheimer's disease. Brain. 2008;131:1630-45. https://doi.org/10.1093/brain/awn016.

31. Moghbel MC, Saboury B, Basu S, Metzler SD, Torigian DA, Langstrom B, et al. Amyloid-beta imaging with PET in Alzheimer's disease: is it feasible with current radiotracers and technologies? Eur J Nucl Med Mol Imaging. 2012;39:202-8. https://doi.org/10.1007/s00259-011-1960-4.

32. Alavi A, Werner TJ, Hoilund-Carlsen PF. What can be and what cannot be accomplished with PET: rectifying ongoing misconceptions. Clin Nucl Med. 2017;42:603-5. https://doi.org/10.1097/rlu. 0000000000001695.

33. Khosravi M, Peter J, Wintering NA, Serruya M, Shamchi SP, Werner TJ, et al. 18F-FDG is a superior indicator of cognitive performance compared to 18F-florbetapir in Alzheimer's disease and mild cognitive impairment evaluation: a global quantitative analysis. J Alzheimers Dis. 2019;70:1197-207. https://doi.org/10. 3233/jad-190220. 
34. Nelson PT, Alafuzoff I, Bigio EH, Bouras C, Braak H, Cairns NJ, et al. Correlation of Alzheimer disease neuropathologic changes with cognitive status: a review of the literature. J Neuropathol Exp Neurol. 2012;71:362-81. https://doi.org/10.1097/NEN. 0b013e31825018f7.

35. Cole GB, Keum G, Liu J, Small GW, Satyamurthy N, Kepe V, et al. Specific estrogen sulfotransferase (SULT1E1) substrates and molecular imaging probe candidates. Proc Natl Acad Sci U S A. 2010;107:6222-7. https://doi.org/10.1073/pnas.0914904107.

36. Jack CR Jr, Barrio JR, Kepe V. Cerebral amyloid PET imaging in Alzheimer's disease. Acta Neuropathol. 2013;126:643-57. https:// doi.org/10.1007/s00401-013-1185-7.

37. Aisen PS. The development of anti-amyloid therapy for Alzheimer's disease : from secretase modulators to polymerisation inhibitors. CNS Drugs. 2005;19:989-96. https://doi.org/10.2165/ 00023210-200519120-00002.

38. Joseph J, Shukitt-Hale B, Denisova NA, Martin A, Perry G, Smith MA. Copernicus revisited: amyloid beta in Alzheimer's disease. Neurobiol Aging. 2001;22:131-46. https://doi.org/10.1016/s01974580(00)00211-6.

39. Castellani RJ, Lee HG, Zhu X, Nunomura A, Perry G, Smith MA. Neuropathology of Alzheimer disease: pathognomonic but not pathogenic. Acta Neuropathol. 2006;111:503-9. https://doi.org/ 10.1007/s00401-006-0071-y.

40. Selkoe DJ, Hardy J. The amyloid hypothesis of Alzheimer's disease at 25 years. EMBO Mol Med. 2016, 8:595-608. https://doi.org/10. 15252/emmm.201606210.

41. Makin S. The amyloid hypothesis on trial. Nature. 2018;559:S4-s7. https://doi.org/10.1038/d41586-018-05719-4.

42. ALZFORUM. Cognitive decline trips up API trials of BACE inhibitor. 2019.

43. Barrio JR. Consensus science and the peer review. Mol Imaging Biol. 2009;11:293. https://doi.org/10.1007/s11307-009-0233-0.

44. Span P. A brain scan may predict Alzheimer's. Should you get one? New York Times; 2019.

45. Hoilund-Carlsen PF, Barrio JR, Gjedde A, Werner TJ, Alavi A. Circular inference in dementia diagnostics. J Alzheimers Dis. 2018;63:69-73. https://doi.org/10.3233/jad-180050.

46. ALZFORUM. Amyloid-PET results lead some to ponder assisted death in Future. 2019.

Publisher's note Springer Nature remains neutral with regard to jurisdictional claims in published maps and institutional affiliations. 